\title{
High cost or frequent attender - both spend resources, but are they linked to work disability? A cohort study from occupational health primary care in Finland
}

\author{
Tiia T. M. Reho ${ }^{1,2^{*}}$ D, Salla A. Atkins ${ }^{3,4}$, Nina Talola ${ }^{1}$, Markku P. T. Sumanen ${ }^{1}$, Mervi Viljamaa ${ }^{2}$ and Jukka Uitti ${ }^{1,5,6}$
}

\begin{abstract}
Background: High use of services is associated with ill health and a number of health problems, but more information is needed on whether high use of services presents a risk for future pensions or disability. We aimed to investigate if defining patients as high cost (HC) or frequent attenders (FA) was more useful in occupational health services (OHS) as a predictor of future disability pension (DP).

Methods: This cohort study used medical record data from a large OHS provider and combined it with register data from the Finnish Centre for Pensions including disability pension decisions. A total of 31,960 patients were included and odds ratios for DP were calculated. Frequent attenders (FA10) were defined as the top decile of visitors according to attendance and high cost ( $\mathrm{HC10}$ ) as the top decile according to costs accrued from service use in 2015. Those patients that were not categorized as FA nor HC, but were eligible for the study were used as the control group (non-FAHC). The outcome measure (disability pensions) was analysed for years 2016-2017.

Results: FA and HC did not significantly differ in their risk for disability pension. Both groups' risk was higher than average users' risk (adjusted OR 3.47 for FA10, OR 2.49 for HC10 and OR 0.33 for controls). Both HC10 and FA10 received half of their disability pensions based on musculoskeletal disorders, while for non-FAHC only $28 \%$ of pensions were granted based on these disorders. The groups overlapped by 68\%.

Conclusions: High utilizers (both FA10 and $\mathrm{HC10}$ ) have an increased likelihood of receiving a future disability pension. The chosen definition is less important than identifying these patients and directing them towards necessary rehabilitation.
\end{abstract}

Keywords: Primary health care, Patient acceptance of health care, Occupational health services, Cohort studies

\footnotetext{
* Correspondence: tiia.reho@gmail.com

${ }^{1}$ Tampere University, Faculty of Medicine and Health Technology, PB 100,

Fl-33014, Tampere, Finland

${ }^{2}$ Pihlajalinna Työterveys, Tampere, Finland

Full list of author information is available at the end of the article
}

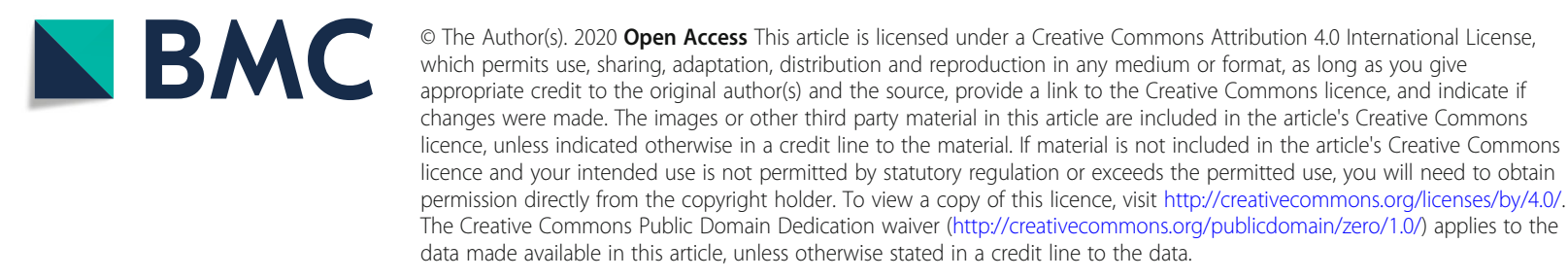




\section{Background}

Use of healthcare services and subsequent healthcare spending are distributed unevenly in the population. Understanding of the phenomenon is crucial as top $10 \%$ of users can create $40 \%$ of the service demand [1,2] and depending on the context, the top 5\% accounts for $50 \%$ [3] and top $10 \%$ up to $70-80 \%$ of costs $[4,5]$. In general, high utilizers have more physical and mental illnesses but also more social problems and overlapping multimorbidity [6, 7]. It appears that both illness related factors and personal and social characteristics affect service use [8]. Although settings, definitions and exact patient's characteristics vary, studies demonstrate that high use of healthcare services relates to an increased need for care and coordination. High utilizers are a vulnerable group of patients with a number of difficulties. Thus, this group should be identified to plan their services better in order to improve their health, and to coordinate services to improve the continuum of care.

Identifying future and current high utilizers of healthcare requires analysis of existing healthcare use patterns. So far, various characterizations have been used to define these patients, including different cut offs for repeated use of services [9] and highest percentiles of cost [10]. International research indicates that patients defined as high-cost ( $\mathrm{HC})$, often have low socio-economic status, are older and have multiple chronic conditions and low perception of health $[10,11]$; while frequent attenders (FA) frequently suffer from psychiatric problems, medically unexplained symptoms and injuries [1, 12]. These findings have mainly been from public or private primary care in settings where clientele varies in terms of ages and sociodemographic backgrounds [10, 13]. As working life sets demands to health and work ability but work has also beneficial health effects [14], studying the working population separately could yield new information about high cost and frequent attenders.

The organization of the Finnish occupational health primary care allows for studying the working population separately from the rest of the population. Primary care services in Finland are provided in three parallel service sectors: municipal, occupational health $(\mathrm{OH})$ and private services. Preventive occupational health services (OHS) are legislated and primary care $\mathrm{OH}$ services are voluntary for organisations, though widely used, and covers up to $90 \%$ of employees [15]. The expense is directly covered by the employer and subsidized by an insurance paid by employers and employees. Previous work has shown that most employees use their $\mathrm{OH}$ unit as their sole primary care provider [16] in particular for issues affecting work ability [17]. The primary care provided should support the $\mathrm{OH}$ service preventive functions, most importantly prevention of working disability [18]. Identifying individuals at risk of future disability through medical record data collected on their primary care visits allows for directing preventive measures, such as early rehabilitation plans, to these patient groups. $\mathrm{HC}$ or FA definitions have not been used thus far in OHS to identify patients at high risk, but identifying high utilisers could have value for service design. However, whether $\mathrm{HC}$ or FA has better predictive value of future disability, is unclear. The ultimate aim of OHS is to prevent disability and disability pensions (DP), and thus we should examine which definition predicts future disability better.

The aim of this study is to examine two definitions of patients who consume more OHS resources than others: high cost and frequent attenders, and to examine how these two categories of patients differ in their characteristics and their risk of future disability pensions.

\section{Methods}

\section{Study design}

This is a cohort study combining routine electronic medical record data with register data.

\section{Setting}

The study used routine medical record data from a large OHS provider, Pihlajalinna. It operates nationwide in Finland serving both municipal and private employees from a variety of industries, and the clientele is fairly representative of the Finnish working population. At the end of 2015 Pihlajalinna had 37 OHS units around the country in both urban and rural areas. In the OHS physicians, nurses, physiotherapists and psychologists mostly with $\mathrm{OH}$ specialization provide both legislated preventive functions and primary care for their clients. The preventive functions of the OHS are mandatory and can be complemented by primary care, which is available to approximately $90 \%$ of employees. Both preventive and primary care functions of the OHS are paid by the employer, and free for the employees [15].

Data collected also includes received decisions on disability pension benefits from the Finnish Centre for Pensions (FCP). A disability pension (DP) may be granted in Finland to individuals with diminished work ability caused by an illness. For a full DP work ability must be reduced by at least $3 / 5$. This DP is permanent and leads to withdrawal from the work force.

\section{Data collection}

All data on face-to-face $\mathrm{OH}$ primary care contacts from 2015 were collected. This data were used to determine the different study groups and the groups were determined according to service use in 2015. Visits to physicians, nurses, psychologists and physiotherapists and consultations with other medical specialists were extracted from electronic medical records by Pihlajalinna. 
The data included visit details such as diagnosis and professional visited, but also the cost (spending) of each consultation and sickness absence days given. In addition to this process data, the employee age, gender, and the employer's main industry and company size were extracted. Pihlajalinna collected the data and sent the pseudonymised data to Tampere University. Data obtained from the FCP contained decisions on DPs (years 2016-2017) and the diagnostic codes associated with the decision [19]. The data were collected at FCP based on social security numbers provided by Pihlajalinna and the data on pensions and were sent pseudonymised to Tampere University.

At the end of 2015 Pihlajalinna had 68,370 employees on their primary care contract list. Approximately three quarters of these (45999) conducted a primary care visit in 2015. We included all patients that were aged 18-68, whose employers had bought a primary care plan, and who had had at least one curative face-to-face contact with an OHS primary care unit in 2015. When defining FA and $\mathrm{HC}$, we excluded all general medical examinations, mandatory occupational safety examinations or those that were not conducted face-to-face (telephone calls, prescription renewals). There are no inpatient periods in the OHS. Only the first (i.e. the main) diagnosis recorded for the visit was considered in the analysis. The recording according to International Classification of Diseases 10th edition (ICD-10) is mandatory and was missing in only $1 \%$ of visits.

\section{Data analysis}

The categorization into different groups (FA, HC, FAHC and non-FAHC) were done based on service use in 2015. FA were defined as the top decile of attenders as in previous studies $[2,9]$, which meant 8 or more visits a year [20]. We used visits to physicians, nurses, physiotherapists and psychologists to define frequent attenders [20]. The top decile was defined as the $10 \%$ of those patients that used services most, in 2015 (belonged to the highest $10 \%$ of patients visiting the OHS). We defined $\mathrm{HC}$ as those patients that ranked in the top $10 \%$ according to their annual spending in the OHS $[10,11]$. All primary care costs (excluding laboratory and imaging costs) created in the OHS in 2015 were summed to define the HC-group [21]. Laboratory and imaging costs were excluded as they could be initiated by health check-ups and not by patient need. The same services were included in defining FA and HC. We also used to the combination definition (FAHC) for those patients that were in the top decile in both categories. The FAHC represent those patients that were both high cost and frequent attenders and includes same patients as the previous groups. As a control group we used patients that were neither FA10 nor $\mathrm{HC} 10$ in the study year
(non-FAHC). These were patients that had used services in 2015 (had at least one face-to-face primary care visit to the OHS in 2015) but could not be considered FA nor HC. They belonged to the $90 \%$ of patients using services less than the highest decile (measured by both frequency of visits and costs).

The study population was divided by sex and age for characterization. Employer industries were categorized according to Statistics Finland/ Statistical classification of economic activities in the European Community (TOL2008/Nace Rev2). We characterized the data using frequencies and chi square -tests. When examining multimorbidity we used the Mann-Whitney $U$-test. The data were carefully revised and any outliers were checked. No extreme outliers were found in the data. The main outcome measure in the analysis was permanent DP as registered on the statistics obtained from the FCP. We included pension decisions given in 20162017. Odds ratios (OR) with $95 \%$ confidence intervals (CI) were calculated for the outcome measure for different FA groups. The results were adjusted for patient age, sex and employer industry and analysed separately. We also used logistic regression to analyze which characteristics were associated with the high use status groups (FA10, HC10, FAHC). Sickness absences for different groups were analysed using logistic regression. Hosmer and Lemeshow goodness-of-fit test was used to evaluate the fitness of the model. Statistical analyses were conducted at Tampere University using IBM SPSS Statistics and R-program. In all analyses $P$ values less than 0.05 were considered statistically significant.

\section{Ethical considerations}

Pirkanmaa hospital district ethics committee (ETL R16041) and the National Institute of Health and Welfare (THL/556/5.05.OO/2016) approved the study. According to Finnish legislation, individual consent was not needed since this a register based study, where no individual participant could be identified.

\section{Results}

In 2015, Pihlajalinna Työterveys had 68,370 clients. Of these, 45,999 had contacted Pihlajalinna during 2015. The study population constituted 31,960 patients who met the inclusion criteria (Fig. 1). In 2015 patients visited Pihlajalinna Työterveys on average 3.7 times and the average cost per person was $213 €$. Of the total visitors, 3617 were categorized as FA10 and 3449 as HC10. The average cost for the $\mathrm{HC} 10$ group was $706 €$ while for FA10 it was $602 €$. The combination group of FAHC constituted 2361 patients (that were both FA10 and HC10) and their average cost was $749 €$. The average cost for the non-FAHC group was $142 €$. The 2361 patients in the FAHC group represent patients that were 


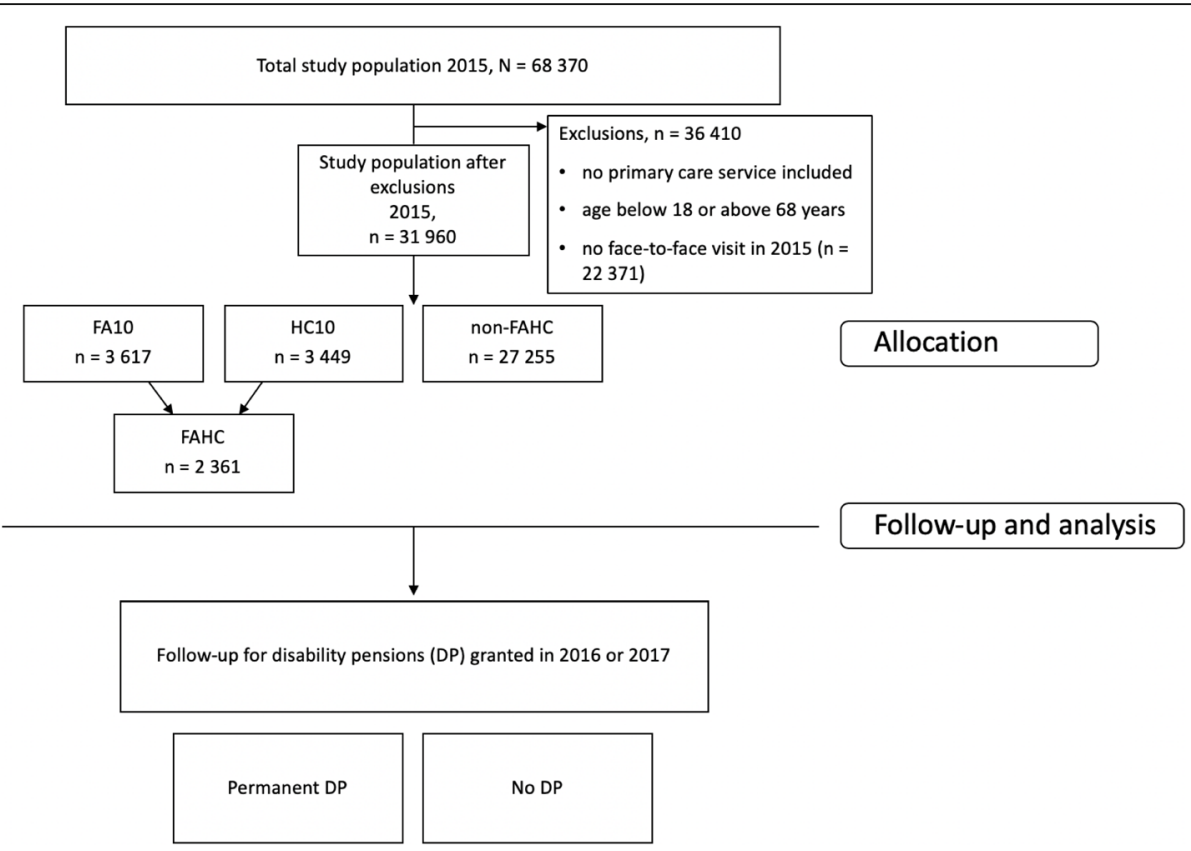

Fig. 1 Flow diagram of the study population. $\mathrm{HC} 10=$ High cost $10 \%$, being in the highest decile in 2015 . FA10 = Frequent attender $10 \%$, being in the highest decile in 2015. FAHC = Combination group of patients that belong to both FA10 and HC10 -groups. Non-FAHC = The control groups, the patients that were neither HC10 nor FA10

both high cost and frequent attenders. These groups overlap with $68 \%$ of patients included in both groups. Table 1 below presents the demographics of the study groups. There are more females in all high use groups compared to other users, and the proportion is greater with $\mathrm{HC10}$ and FAHC groups than FA10. The age groups above 45 are accentuated in the HC10s.

As expected, all diagnostic groups are associated with high use of services. However, this association is enhanced in diseases of the musculoskeletal system (M00-M99) and mental disorders (F00-F99) (Table 2). The differences between the high use groups are significant in mental disorders and injuries. The association with mental disorders was stronger for FA10 than HC10. On the other hand, diseases of the musculoskeletal system are more closely associated with FAHC than HC10. When suffering from diseases of the musculoskeletal system or mental disorders one was likely to be both frequent attender and high cost. All high use status groups (FA, HC, FAHC) had a median of three different ICD-10 diagnoses while the group of non-FA had a median of one $(p<0.001)$.

Other factors associated with FA10 and $\mathrm{HC} 10$ are shown in Table 3. Being female was associated with both FA10 and HC10. There is an association of specialist consultation and $\mathrm{HC} 10$ which appears enhanced compared to FA10. All high use status groups have more permanent disability pensions than the control group (Table 1).
All high use status groups (FA10, HC10 and FAHC) had more long sickness absences than non-FAHC. The results show $53 \%$ of FA10, 37\% of $\mathrm{HC} 10$ and $56 \%$ of FAHC groups had a sickness absence longer than 15 days. Table 4 shows characteristics associated with sickness absences over 15 days in different groups. Female sex and morbidity (measured by the number of different diagnoses given by a physician) were associated with FA status in sickness absences over 15 days.

Being FA10, HC10 or FAHC increases the likelihood of receiving DP in the following 2 years as seen in Table 5. In the adjusted ratios the differences between the groups are marginal but the association with FAHC status appears stronger than the other high use groups. The increased risk turned into cases would mean an additional 35,36 and 40 disability cases for the status FAHC, FA10 and HC10 respectfully.

When looking at the diagnoses leading to permanent DP majority of high cost and frequent attenders' disability pensions are due to diseases of the musculoskeletal system $(49,50$ and $51 \%$ for FA10, HC10 and FAHC respectively) while for non-FAHC the proportion was $28 \%$. The distribution of diagnoses leading to permanent DP is more widespread for non-FAHC and they appear to have particularly more diseases of the circulatory system leading to DP (17\%) than high cost or frequent attenders' groups (less than 6\%). 
Table 1 Characteristics of frequent attender 10\% (FA10), high cost 10\% (HC10) and patients in both categories (FAHC) compared with non-frequent attender and non-high cost users (non-FAHC), $N=31,960$

\begin{tabular}{|c|c|c|c|c|c|c|c|c|}
\hline \multirow[b]{2}{*}{ Characteristics } & \multicolumn{2}{|c|}{$\begin{array}{l}\text { FA10 } \\
n=3617\end{array}$} & \multicolumn{2}{|c|}{$\begin{array}{l}\mathrm{HC10} \\
n=3449\end{array}$} & \multicolumn{2}{|c|}{$\begin{array}{l}\text { FAHC } \\
n=2361\end{array}$} & \multicolumn{2}{|c|}{$\begin{array}{l}\text { non-FAHC } \\
n=27,255\end{array}$} \\
\hline & $\bar{n}$ & $\%$ & $\mathrm{n}$ & $\%$ & $\mathrm{n}$ & $\%$ & $\mathrm{n}$ & $\%$ \\
\hline \multicolumn{9}{|l|}{ Sex } \\
\hline Male & 1811 & 50 & 1622 & 47 & 1120 & 47 & 15,994 & 59 \\
\hline Female & 1806 & 50 & 1827 & 53 & 1241 & 53 & 11,261 & 41 \\
\hline \multicolumn{9}{|l|}{ Age } \\
\hline $18-34$ & 840 & 23 & 654 & 19 & 505 & 22 & 8158 & 30 \\
\hline $35-44$ & 908 & 25 & 828 & 24 & 589 & 25 & 6502 & 24 \\
\hline $45-54$ & 983 & 27 & 1032 & 30 & 666 & 28 & 7288 & 27 \\
\hline $55-68$ & 886 & 25 & 935 & 27 & 601 & 26 & 5307 & 19 \\
\hline \multicolumn{9}{|l|}{ Company size } \\
\hline $0-10$ & 227 & 6 & 304 & 9 & 139 & 6 & 3851 & 14 \\
\hline $11-50$ & 862 & 24 & 861 & 24 & 547 & 23 & 7735 & 28 \\
\hline $51-250$ & 1111 & 31 & 1054 & 31 & 756 & 32 & 6752 & 25 \\
\hline$>250$ & 1417 & 39 & 1230 & 36 & 919 & 39 & 8917 & 33 \\
\hline \multicolumn{9}{|l|}{ Professionals visited in 2015 * } \\
\hline Doctor & 3609 & 100 & 3436 & 100 & 2358 & 100 & 24,790 & 91 \\
\hline Nurse & 2068 & 57 & 1512 & 44 & 1290 & 55 & 7804 & 29 \\
\hline Physiotherapist consultation & 1489 & 41 & 1073 & 31 & 931 & 39 & 2726 & 10 \\
\hline Psychologist consultation & 232 & 6 & 274 & 8 & 186 & 8 & 737 & 3 \\
\hline Specialist consultation & 901 & 25 & 998 & 29 & 713 & 30 & 1939 & 7 \\
\hline \multicolumn{9}{|l|}{$\mathrm{OH}$ collaborative negotiation } \\
\hline No & 3294 & 91 & 3150 & 91 & 2105 & 89 & 27,032 & 99 \\
\hline Yes & 323 & 9 & 299 & 9 & 256 & 11 & 223 & 1 \\
\hline Permanent disability pension (2016-2017) & 49 & 1 & 52 & 2 & 43 & 2 & 96 & 0 \\
\hline \multicolumn{9}{|l|}{ Industry } \\
\hline Manufacturing & 1398 & 39 & 1070 & 31 & 864 & 37 & 8304 & 31 \\
\hline $\begin{array}{l}\text { Wholesale and retail trade; repair of motor } \\
\text { vehicles and motorcycles }\end{array}$ & 313 & 9 & 358 & 10 & 198 & 8 & 3054 & 11 \\
\hline Professional, scientific and technical activities & 183 & 5 & 193 & 6 & 123 & 5 & 1610 & 6 \\
\hline $\begin{array}{l}\text { Public administration and defense; compulsory } \\
\text { social security }\end{array}$ & 346 & 10 & 305 & 9 & 231 & 10 & 2043 & 7 \\
\hline Human health and social work activities & 433 & 12 & 417 & 12 & 294 & 12 & 2461 & 9 \\
\hline Others & 944 & 26 & 1106 & 32 & 651 & 28 & 9783 & 36 \\
\hline
\end{tabular}

The results of the study are presented according to the latest industry classification system from 2008 that is based on the Statistical classification of economic activities (NACE Rev. 2)

*A patient might have visited more than one professional

The cost of HC10 group compared to any other user was due to physiotherapist visits $(9.7 \%$ for $\mathrm{HC} 10$ and $1.5 \%$ for others) and other medical specialist visits $(4.0 \%$ for $\mathrm{HC} 10$ and $1.9 \%$ for others). On the other hand, the cost due to physician visits was smaller for $\mathrm{HC} 10$ (76.1\%) compared to others $(82.0 \%)$. As a whole, when laboratory and imaging costs were excluded, most costs were due to physician visits.

\section{Discussion}

This study found that high use of services, whether measured by attendance rates or costs, is associated with disability pensions in the following 2 years. The associated risk is fairly similar regardless of the chosen definition. In addition, the characteristics between the high cost and frequent attenders' groups are fairly similar. These findings suggest that the chosen definition is less 
Table 2 Diagnoses associated with frequent attender 10\% (FA10), high cost users (HC10) and both FA10 and HC10 (registered for physician consultations, adjusted for age, sex and industry), $n=29,380$

\begin{tabular}{|c|c|c|c|c|c|c|}
\hline \multirow[b]{2}{*}{ ICD-10 } & \multicolumn{2}{|c|}{ FA10 } & \multicolumn{2}{|c|}{$\mathrm{HC} 10$} & \multicolumn{2}{|c|}{$\begin{array}{l}\text { FAHC } \\
\text { (FA10 \& HC10) }\end{array}$} \\
\hline & OR & $95 \% \mathrm{Cl}$ & OR & $95 \% \mathrm{Cl}$ & OR & $95 \% \mathrm{Cl}$ \\
\hline A00-B99 Certain infectious and parasitic diseases & 2.43 & $2.18-2.71$ & 2.34 & $2.09-2.63$ & 2.67 & $2.36-3.03$ \\
\hline F00-F99 Mental and behavioural disorders & 4.34 & $3.96-4.76$ & 3.52 & $3.19-3.87$ & 4.16 & $3.74-4.62$ \\
\hline G00-G99 Diseases of the nervous system & 2.74 & $2.44-3.08$ & 3.41 & $3.04-3.83$ & 3.32 & $2.91-3.77$ \\
\hline 100-199 Diseases of the circulatory system & 1.82 & $1.63-2.03$ & 2.09 & $1.88-2.33$ & 2.14 & $1.89-2.43$ \\
\hline J00-J99 Diseases of the respiratory system & 2.47 & $2.30-2.66$ & 2.31 & $2.15-2.49$ & 2.98 & $2.73-3.26$ \\
\hline K00-K93 Diseases of the digestive system & 2.45 & $2.18-2.75$ & 2.76 & $2.45-3.10$ & 2.82 & $2.47-3.21$ \\
\hline L00-L99 Diseases of the skin and subcutaneous tissue & 2.18 & $1.97-2.41$ & 2.22 & $2.00-2.46$ & 2.45 & $2.19-2.75$ \\
\hline M00-M99 Diseases of the musculoskeletal system and connective tissue & 4.09 & $3.79-4.41$ & 3.90 & $3.61-4.21$ & 4.67 & $4.24-5.13$ \\
\hline R00-R99 Symptoms, signs and abnormal clinical and laboratory findings, not elsewhere classified & 2.92 & $2.69-3.17$ & 3.02 & $2.78-3.28$ & 3.41 & $3.11-3.75$ \\
\hline S00-T98 Injury, poisoning and certain other consequences of external causes & 3.11 & $2.87-3.38$ & 2.03 & $1.86-2.22$ & 2.42 & $2.20-2.68$ \\
\hline
\end{tabular}

OR Odds ratio, $\mathrm{Cl}$ Confidence interval

The diagnostic groups were used as dummy variables (No $=$ reference group $=1.00)$

ICD-10 = International Classification of Diseases

The 10 largest ICD-10 groups are presented

important than taking action in identifying these groups and planning necessary measures to maintain work ability.

To our knowledge this is the first study to analyze differences in disability pension risks between high cost and frequent attender groups. We chose to analyze the differences in relation to disability pension as this reflects the risks linked to high use of services; it is not only a question of resources and their management, but high use of services reflects health related problems that demand attention. The elevated risk of future disability pension of both these groups indicates that the service demand is real and should be taken seriously. On the other hand, understanding which definition reflects DP in the near future better is essential for deciding which definition to use in identifying high utilizers in $\mathrm{OH}$ services. This study provides data for service providers to choose the definition that indicates risk of disability more accurately than the other. Based on this $\mathrm{OH}$ services can identify candidates for rehabilitative actions. Prevention of future disability is one of the key aims of OHS [18] and service use is a possible marker in identification of those individuals that need more supportive measures. Our results indicate that the differences between the definitions in this context are minimal between frequent attender and high cost users - the

Table 3 Factors associated with frequent attender and high cost status, $n=31,960$

\begin{tabular}{|c|c|c|c|c|c|c|c|c|c|c|c|c|}
\hline \multirow[b]{3}{*}{ Factor } & \multicolumn{4}{|c|}{ Frequent attender 10\% (FA10) } & \multicolumn{4}{|c|}{ High cost user 10\% (HC10) } & \multicolumn{4}{|c|}{$\begin{array}{l}\text { Frequent attender High cost } \\
\text { (FAHC) }\end{array}$} \\
\hline & \multicolumn{2}{|c|}{ Crude ratios } & \multicolumn{2}{|c|}{ Adjusted ratios* } & \multicolumn{2}{|c|}{ Crude ratios } & \multicolumn{2}{|c|}{ Adjusted ratios* } & \multicolumn{2}{|c|}{ Crude ratios } & \multicolumn{2}{|c|}{ Adjusted ratios* } \\
\hline & OR & $95 \% \mathrm{Cl}$ & OR & $95 \% \mathrm{Cl}$ & OR & $95 \% \mathrm{Cl}$ & OR & $95 \% \mathrm{Cl}$ & OR & $95 \% \mathrm{Cl}$ & OR & $95 \% \mathrm{Cl}$ \\
\hline \multicolumn{13}{|l|}{ Sex } \\
\hline Male & 1.00 & & 1.00 & & 1.00 & & 1.00 & & 1.00 & & 1.00 & \\
\hline Female & 1.38 & $1.29-1.49$ & 1.41 & $1.31-1.51$ & 1.59 & $1.48-1.71$ & 1.59 & $1.48-1.71$ & 1.53 & $1.41-1.67$ & 1.55 & $1.42-1.69$ \\
\hline \multicolumn{13}{|l|}{ Age } \\
\hline $18-34$ & 1.00 & & 1.00 & & 1.00 & & 1.00 & & 1.00 & & 1.00 & \\
\hline $35-44$ & 1.33 & $1.21-1.47$ & 1.34 & $1.21-1.48$ & 1.58 & $1.42-1.76$ & 1.60 & $1.44-1.78$ & 1.43 & $1.26-1.61$ & 1.44 & $1.27-1.63$ \\
\hline $45-54$ & 1.27 & $1.15-1.40$ & 1.26 & $1.14-1.39$ & 1.76 & $1.59-1.95$ & 1.77 & $1.60-1.96$ & 1.43 & $1.27-1.61$ & 1.43 & $1.26-1.61$ \\
\hline $55-68$ & 1.55 & $1.41-1.72$ & 1.54 & $1.41-1.72$ & 2.17 & $1.95-2.41$ & 2.16 & $1.95-2.40$ & 1.74 & $1.54-1.96$ & 1.72 & $1.52-1.95$ \\
\hline Specialist consultation & 3.90 & $3.57-4.25$ & 3.89 & $3.56-4.24$ & 5.05 & $4.64-5.50$ & 5.13 & $4.70-5.59$ & 4.88 & $4.43-5.38$ & 4.87 & $4.41-5.37$ \\
\hline
\end{tabular}

${ }^{*}$ Adjusted for age, sex and industry when possible, $\mathrm{OR}=$ Odds ratio, $\mathrm{Cl}=$ Confidence interval, $1.0=$ reference group 
Table 4 Sickness absences $>15$ days associated with FA10, HC10 and FAHC status in logistic regression model (adjusted for age, field of industry and cancer dg (CO0-C97) and number of different ICD-10 diagnoses given by physicians), $n=16,111$

\begin{tabular}{|c|c|c|c|c|c|c|}
\hline \multicolumn{2}{|c|}{ FA10 vs. Non-FA10 } & \multicolumn{2}{|c|}{ HC10 vs. Non-HC10 } & \multicolumn{2}{|c|}{ FAHC vs. Non-FAHC } & \multirow[b]{2}{*}{$95 \% \mathrm{Cl}$} \\
\hline & OR & $95 \% \mathrm{Cl}$ & OR & $95 \% \mathrm{Cl}$ & OR & \\
\hline \multicolumn{7}{|l|}{ Sex } \\
\hline Male & 1.00 & & 1.00 & & 1.00 & \\
\hline Female & 1.32 & $1.01-1.72$ & 1.59 & $1.23-2.05$ & 1.57 & $1.18-2.09$ \\
\hline Number of different ICD-10 diagnoses given by physicians & 1.91 & $1.77-2.07$ & 1.67 & $1.55-1.79$ & 1.87 & $1.73-2.04$ \\
\hline
\end{tabular}

combined definition (FAHC) appears to have the highest likelihood of having a future disability pension, but the differences between the groups are relatively small. Based on our study, it appears less important whether high use is defined according to attendance rate or costs, and the choice can be made based on data more easily accessible.

When looking at the diagnoses leading to permanent disability pension the high utilization groups differ from each other only slightly. However, they differ substantially from the control group (non-FAHC) portraying more musculoskeletal disorders leading to disability pension and fewer of any other diagnostic group leading to disability. There is little previous research on the associations of high use of services and disability pensions. Existing studies suggest that frequent attendance is associated with being on disability pension [22, 23]. In addition, a Swedish study from general practice setting showed [24] that frequent attenders are more likely to be on long sick leave or on disability pension but the diagnoses leading to this withdrawal from the work force were unknown. Our study indicates that although the differences between the different high utilizer groups are small, they differ from the other users of $\mathrm{OH}$ services by having more musculoskeletal disorders severe enough to cause permanent disability. This indicates that in

Table 5 Factors associated with permanent disability pension (DP) for frequent attender 10\% (FA10), high cost 10\% (HC10) and both FA10 and HC10 (FAHC), $n=31,960$

\begin{tabular}{lllll}
\hline & \multicolumn{4}{l}{ Permanent disability pension } \\
\cline { 2 - 5 } & \multicolumn{2}{l}{ Crude ratios } & \multicolumn{2}{l}{ Adjusted ratios* } \\
\hline Factor & OR & $95 \% \mathrm{Cl}$ & OR & $95 \% \mathrm{Cl}$ \\
Sex, Female & 0.98 & $0.71-1.35$ & & \\
Age & 1.17 & $1.14-1.20$ & & \\
FA10** & 3.69 & $2.63-5.19$ & 3.47 & $2.46-4.91$ \\
HC10 $^{* *}$ & 4.26 & $3.05-5.97$ & 3.50 & $2.49-4.93$ \\
FAHC $^{* *}$ & 4.93 & $3.46-7.03$ & 4.55 & $3.17-6.54$ \\
non-FAHC & 0.28 & $0.20-0.39$ & 0.33 & $0.24-0.46$ \\
\hline
\end{tabular}

OR Odds ratio, $\mathrm{Cl}$ Confidence interval

${ }^{*}$ Adjusted for sex, age and industry

** Hosmer and Lemenshow $<0.05$ particular high utilizers suffering from musculoskeletal disorders should be identified and that careful evaluation of necessary rehabilitative actions is needed.

When examining the visits, diseases of the musculoskeletal system are associated with frequent attenders and the combination group, FAHC, in particular. The connection with mental disorders is stronger also for frequent attenders than for high cost users. To our knowledge there are no previous studies comparing differences in diagnoses of frequent attenders and high cost users. Previous studies have shown that frequent attenders are prone to injuries [12] and our study indicates that the association to injuries is stronger for frequent attenders than high cost. On the other hand, the association of high cost and neurological symptoms has been described earlier [21, 25]. Our results add to this by showing that the association is stronger for high cost than frequent attenders. As expected, multimorbidity was present in both FA and $\mathrm{HC}$ groups.

As a whole the HC10 group constituted $37 \%$ on all the costs while the FA10 group constituted $33 \%$ of the costs. These groups overlapped so that $68 \%$ of frequent attenders were also high cost (FAHC, $n=2361$ ). The average costs for FA10 or $\mathrm{HC10}$ was four to five times higher than the average users' cost. Comparison between the high utilizer status groups indicates that when laboratory and imaging costs are excluded, the differences between the groups in costs and background characteristics are rather small. There are more females in high cost and combination group and female gender is associated with being high utilizer in general. A previous study inspected the association of FA-status with female gender in $\mathrm{OH}$ services [20] and this study verifies the finding with also high cost and combination group in OHS. However, previously there are differing results regarding sex and high use of services depending on the setting [6, $21,25]$. Being older is associated with high cost in particular [21, 25] and our study verifies the association of older age with high cost also in OHS. Specialist consultations are more expensive than usual visits in the $\mathrm{OH}$ services, which can explain the association of $\mathrm{HC} 10$ with specialist consultation, a connection also shown previously [25]. Specialist visits may also generate follow-up 
visits and further examinations, which may add to this connection.

The strengths of our study are the large study population representing a variety of industries and urban and rural areas around Finland. Thus, the study population is fairly representative of the working population in Finland. Although we used data from one service provider, it allows for comparing different definitions. In addition, the amount of missing data was minimal. On the other hand, we were not able to include laboratory and imagining costs as we could not trace if they were associated with mandatory safety check-ups part of preventive care, which means that the groups might include different patients if these costs were included. As disability pensions is a fairly uncommon endpoint for any of the groups, this should be kept in mind in interpretation of the results. The goodness of fit of the model used in the analysis is not the best possible, but this analysis was chosen because of the familiarity and familiar interpretation. It is well established that sickness absences are closely associated with risk of future disability. In the analyses, this was not taken into account for any of the groups. We have previously detected that the disability pension risk associated with frequent attendance is closely linked to long sickness absences, which are more common for frequent attenders [26]. Next step should be to study whether already existing intervention strategies [27] are of use for high service utilizers or should there be targeted measures for these groups.

\section{Conclusions}

Service use indicates risk of disability pension in the future and allows identification of groups that might benefit from rehabilitation. Defining these factors that are associated with future disability and might indicate rehabilitative needs prior to sickness absences, allows identification of these groups and constructing early rehabilitative and treatment plans. It is not nearly enough that we identify high utilisers from other patients, but we need to use this to enhance their services and coordination. At least in the OHS the aim should be to identify the individuals that might benefit most from rehabilitation and care coordination.

Service use could also be used as a marker for rehabilitative needs in addition to sickness absences allowing for early interventions. It appears less important whether high use is defined according to attendance rate or costs.

\footnotetext{
Abbreviations

$\mathrm{Cl}$ : Confidence interval; FA10: Frequent attender 10\% (patients in the top decile of annual visits to healthcare professionals); GP: General practice; MUPS: Medically unexplained physical symptoms; $\mathrm{OH}$ : Occupational health; OHS: Occupational health services; OR: Odds ratios; HC: High cost (patients that ranked in the top $10 \%$ according to their annual spending in the $\mathrm{OHS}$ ); DP: Disability pension; FCP: Finnish Centre for Pensions; ICD-10: International Classification of Diseases, 10th edition
}

\section{Acknowledgements}

The authors acknowledge the participation of the occupational health staff in the study and all the individual clients who are part of this study.

\begin{abstract}
Authors' contributions
The study was conceptualized by $J U$ and the study design was planned by all the authors (TR, SA, NT, MS, MV and JU). Planning of data collection and analysis was done by all authors (TR, SA, NT, MS, MV and JU). NT analyzed the data. TR wrote the first draft and all authors (TR, SA, NT, MS, MV and JU) contributed to the final version by revising and commenting on the draft. All authors approved the final version.
\end{abstract}

\section{Funding}

This study is part of the "Effectiveness and Indicators of Occupational Health Services" supported by the European Social Fund [reference number S20659]. This stuyd was also supported by Valtion tutkimusrahoitus (9X057). The funders had no role in the design of the study nor collection, analysis, and interpretation of data or in writing the manuscript.

\section{Availability of data and materials}

The data that support the findings of this study are available from Pihlajalinna Työterveys but restrictions apply to the availability of these data, which were used under license for the current study, and so are not publicly available. Data are however available from the authors upon reasonable request and with permission of Pihlajalinna Työterveys.

\section{Ethics approval and consent to participate}

The ethics committee of Pirkanmaa Hospital District (ETL R16041) and the National Institute of Health and Welfare (THL/556/5.05.0O/2016) approved the study. Based on Finnish legislation (Personal Data Act, Finland, 22.4.1999) individual consent is unnecessary since no individual could be identified due to the size of the study population.

\section{Consent for publication}

Not applicable.

\section{Competing interests}

The Authors declare that there is no conflict of interest.

\section{Author details}

${ }^{1}$ Tampere University, Faculty of Medicine and Health Technology, PB 100, FI-33014, Tampere, Finland. Pihlajalinna Työterveys, Tampere, Finland. ${ }^{3}$ Tampere University, New Social Research and Faculty of Social Sciences, Tampere, Finland. ${ }^{4}$ Department of Global Public Health, Karolinska Institutet, Stockholm, Sweden. ${ }^{5}$ Finnish Institute of Occupational Health, Tampere, Finland. ${ }^{6}$ Clinic of Occupational Medicine, Tampere University Hospital, Tampere, Finland.

Received: 31 May 2019 Accepted: 17 May 2020

Published online: 24 May 2020

\section{References}

1. Smits FT, Brouwer HJ, ter Riet G, van Weert HC. Epidemiology of frequent attenders: a 3-year historic cohort study comparing attendance, morbidity and prescriptions of one-year and persistent frequent attenders. BMC Public Health. 2009:9:36.

2. Vedsted $P$, Christensen MB. Frequent attenders in general practice care: a literature review with special reference to methodological considerations. Public Health. 2005;119:118-37.

3. Cohen S, YU W. STATISTICAL BRIEF \#354: The Concentration and Persistence in the Level of Health Expenditures over Time: Estimates for the U.S. Population, 2008-2009. https://meps.ahrq.gov/data_files/publications/st354/ stat354.shtml. Accessed 27 Jan 2019.

4. Leskelä R-L, Komssi V, Sandström S, Pikkujämsä S, Haverinen A, Olli S-L, et al. Paljon sosiaali- ja terveyspalveluja käyttävät asukkaat Oulussa. [heavy users of social and health care services in the city of Oulu.] (in Finnish with English summary). Suom Lääkäril. 2013;68:3163-9.

5. Berk ML, Monheit AC. The concentration of health care expenditures, revisited. Health Aff. 2001;20:9-18. 
6. Gill D, Sharpe M. Frequent consulters in general practice:a systematic review of studies of prevalence, associations and outcome. J Psychosom Res. 1999; 47:115-30.

7. Droomers M, Westert GP. Do lower socioeconomic groups use more health services, because they suffer from more illnesses? Eur J Pub Health. 2004;14: 311-3.

8. Kersnik J, Scvab I, Vegnuti M. Frequent attenders in general practice: quality of life, patient satisfaction, use of medical services and GP characteristics. Scand J Prim Health Care. 2001;19:174-7.

9. Luciano JV, Fernández A, Pinto-Meza A, Luján L, Bellón JA, García-Campayo J, et al. Frequent attendance in primary care: comparison and implications of different definitions. Br J Gen Pract. 2010;60:e49-55.

10. Rosella LC, Fitzpatrick T, Wodchis WP, Calzavara A, Manson H, Goel V. High-cost health care users in Ontario, Canada: demographic, socioeconomic, and health status characteristics. BMC Health Serv Res. 2014; 14:532.

11. Fitzpatrick T, Rosella LC, Calzavara A, Petch J, Pinto AD, Manson H, et al. Looking beyond income and education socioeconomic status gradients among future high-cost users of health care. Am J Prev Med Am J Prev Med. 2015;49:161-71.

12. Bergh H, Baigi A, Marklund B. Consultations for injuries by frequent attenders are found to be medically appropriate from general practitioners' perspective. Scand J Public Health. 2005;33:228-32.

13. Bergh $H$, Marklund $B$. Characteristics of frequent attenders in different age and sex groups in primary health care. Scand J Prim Health Care. 2003;21:171-7.

14. Ross CE, Mirowsky J. Does employment affect health? J Health Soc Behav. 1995;36:230-43

15. Lappalainen K, Aminoff M, Hakulinen H, Hirvonen M, Räsänen K, Sauni R, et al. Työterveyshuolto Suomessa vuonna 2015. Helsinki: [occupational healthcare in Finland 2015 report] (in Finnish with english summary). Työterveyslaitos;2016.

16. Ikonen A, Räsänen $K$, Manninen $P$, Rautio M, Husman P, Ojajärvi A, et al. Use of health services by Finnish employees in regard to health-related factors: the population-based health 2000 study. Int Arch Occup Environ Health. 2013;86:451-62.

17. Kimanen A, Rautio M, Manninen P, Räsänen K, Husman P, Husman K. Primary care visits to occupational health physicians and nurses in Finland. Scand J Public Health. 2011;39:525-32.

18. Martimo K-P, Mäkitalo J. The status of occupational health services in Finland and the role of the Finnish Institute of Occupational Health in the development of occupational health services. Helsinki: Finnish Institute of Occupational Health; 2014.

19. Finnish Centre for Pensions. Earnings-related pension recipients in Finland 2015. Helsinki: Finnish Centre for Pensions; 2016

20. Reho T, Atkins S, Talola N, Sumanen M, Viljamaa M, Uitti J. Frequent attenders in occupational health primary care - a cross-sectional study. Scand J Public Health. 2019 Feb;47(1):28-36. https://doi.org/10.1177/ 1403494818777436

21. Chechulin $Y$, Nazerian A, Rais S, Malikov K. Predicting patients with high risk of becoming high-cost healthcare users in Ontario (Canada). Healthc Policy. 2014;9:68-79.

22. Karlsson $\mathrm{H}$, Lehtinen $\mathrm{V}$, Joukamaa M. Frequent attenders of Finnish public primary health-care - Sociodemographic characteristics and physical morbidity. Fam Pract. 1994:11:424-30.

23. Jyväsjärvi S, Keinänen-Kiukaanniemi S, Väisänen E, Larivaara P, Kivelä SL. Frequent attenders in a Finnish health Centre: morbidity and reasons for encounter. Scand J Prim Health Care. 1998;16:141-8.

24. Bergh H, Baigi A, Månsson J, Mattsson B, Marklund B. Predictive factors for long-term sick leave and disability pension among frequent and normal attenders in primary health care over 5 years. Public Health. 2007;121:25-33.

25. Reid R, Evans R, Barer M, Sheps S, Kerluke K, McGrail K, et al. Conspicuous consumption: characterizing high users of physician services in one Canadian province. J Heal Serv Res Policy. 2003:8:215-24.

26. Reho TTM, Atkins SA, Talola N, Sumanen MPT, Viljamaa M, Uitti J. Frequent attenders at risk of disability pension: a longitudinal study combining routine and register data. Scand J Public Health. 2019;January:1-9.

27. de Boer AGEM. An occupational health intervention programme for workers at risk for early retirement; a randomised controlled trial. Occup Environ Med. 2004;61:924-9.

\section{Publisher's Note}

Springer Nature remains neutral with regard to jurisdictional claims in published maps and institutional affiliations.

\section{Ready to submit your research? Choose BMC and benefit from:}

- fast, convenient online submission

- thorough peer review by experienced researchers in your field

- rapid publication on acceptance

- support for research data, including large and complex data types

- gold Open Access which fosters wider collaboration and increased citations

- maximum visibility for your research: over $100 \mathrm{M}$ website views per year

At $\mathrm{BMC}$, research is always in progress.

Learn more biomedcentral.com/submissions 